\title{
Effects of hypoxia on the immunomodulatory properties of adipose tissue-derived mesenchymal stem cells
}

\author{
Marieke Roemeling-van Rhijn ${ }^{1}$, Fane K. F. Mensah ${ }^{1}$, Sander S. Korevaar ${ }^{1}$, Maarten J. Leijs ${ }^{2}$, \\ Gerjo J. V. M. van Osch ${ }^{2}$, Jan N. M. IJzermans ${ }^{3}$, Michiel G. H. Betjes' ${ }^{1}$, Carla C. Baan ${ }^{1}$, Willem Weimar $^{1}$ and $^{2}$ \\ Martin J. Hoogduijn ${ }^{1}$
}

\author{
${ }^{1}$ Department of Internal Medicine, Erasmus MC, Rotterdam, Netherlands \\ 2 Department of Orthopedics, Erasmus MC, Rotterdam, Netherlands \\ ${ }^{3}$ Department of General Surgery, Erasmus MC, Rotterdam, Netherlands
}

Edited by:

José Mordoh, Fundación Instituto

Leloir, Argentina

Reviewed by:

Luuk Hilbrands, Radboud University

Nijmegen Medical Centre,

Netherlands

María Marcela Barrio, Fundación

Cáncer FUCA, Argentina

Sébastien André, University Pierre

and Marie Curie, France

*Correspondence:

Marieke Roemeling-van Rhijn, Department of Internal Medicine, Transplantation Laboratory, Erasmus MC, Room No 319, P.O. Box 2040, 3000 CA Rotterdam, Netherlands e-mail:m.vanrhijn@erasmusmc.nl
Adipose tissue-derived mesenchymal stem cells (ASC) are of great interest as a cellular therapeutic agent for regenerative and immunomodulatory purposes. The function of ASC adapts to environmental conditions, such as oxygen tension. Oxygen levels within tissues are typically much lower than under standard culture conditions and ASC used for therapy therefore encounter a change from normoxic to hypoxic conditions. The effect of hypoxia on the regenerative potential of ASC has been investigated in a number of studies. The effect of hypoxia on the immunomodulatory function of ASC, however, remains to be determined. In the present study the effect of hypoxic (1\% oxygen) culture conditions on human ASC was examined. ASC showed no signs of toxicity under low oxygen levels and no major immunophenotypical changes were observed, apart from a down regulation of the marker CD105. Oxygen tension had no effect on the proliferation of ASC and colony forming unit efficiency remained the same under 1 and $20 \%$ oxygen. Under both oxygen levels ASC were capable of strong upregulation of the immunomodulatory molecules indoleamine 2,3-dioxygenase (IDO) and programed death ligand-1 upon stimulation with IFN- $\gamma$ and TNF- $\alpha$, and, in addition, IDO activity as measured by the accumulation of L-kynurenine was not affected under hypoxia. The ability of ASC to inhibit anti-CD3/CD28 stimulated $\mathrm{CD}^{+}$and $\mathrm{CD} 8^{+} \mathrm{T}$ cell proliferation was not hampered by hypoxia. The results of the present study demonstrate that the immunosuppressive capacity of ASC is maintained under hypoxic conditions. These findings are important for the therapeutic use of ASC and may be applied for the in vitro generation of ASC with improved functionality for therapeutic use.

Keywords: mesenchymal stem cells, cell therapy, hypoxia, immune modulation, oxygen level

\section{INTRODUCTION}

Mesenchymal stem cells (MSC) have emerged as cells with great clinical potential. In vitro studies have demonstrated the immunosuppressive and regenerative capacities of MSC. Currently, MSC have been evaluated as a cell therapeutic agent in many medical fields including graft versus host disease, solid organ transplantation, and Crohn's disease (1-3). MSC can be isolated from a wide range of tissues $(4,5)$, of which bone marrow is the classical, and most frequently used source. However, bone marrow aspiration is invasive and is accompanied with donor morbidity (6). In contrast, adipose tissue is more accessible, has a higher yield of MSC, and adipose tissue-derived mesenchymal stem cells (ASC) share many properties with their bone marrow derived counterparts $(7,8)$. Adipose tissue is therefore the favored source of MSC in an increasing number of studies (9-11). To obtain sufficient numbers of MSC for research and certainly clinical application the cells are culture expanded. Culture conditions, however, have striking effects on the phenotype and function of MSC. Advantage of this can be taken by modulating culture conditions in such a way that cells with superior functionality are obtained.
Oxygen concentration is an important environmental factor that affects MSC. While MSC are normally cultured under $20 \%$ oxygen tension, tissue-resident MSC face much lower oxygen concentrations. Oxygen tension in adipose tissue, for instance, fluctuates depending on blood flow, but varies typically between 3 and $11 \%(12)$. Lower oxygen concentrations can occur in the incidence of injury. It has been demonstrated that hypoxic conditions affect the function of bone marrow derived MSC. Culturing under $1 \%$ oxygen reduces MSC senescence while it increases proliferation and maintains the differentiation properties of the cells (13). Similar results have been obtained for MSC derived from adipose tissue and Wharton's jelly (14-16). This suggests that MSC are triggered by injury-induced hypoxic conditions to expand and eventually differentiate. MSC have also been shown to enhance their angiogenic potential under hypoxia by increasing their secretion of vascular endothelial growth factor (VEGF) and bFGF (17).

Tissue trauma is almost without exception followed by inflammation. Inflammation in its turn is a major activator of the immunosuppressive capacity of MSC (18), which thereby allows regeneration by inhibiting immune activity. It is however 
unknown whether hypoxia, occurring before the initiation of inflammation, alters the immunosuppressive capacities of MSC. As these capacities are essential for MSC therapy, it is important to evaluate the effect of hypoxia on MSC. Therefore, in the present study we examined the effect of low oxygen concentrations on the phenotype and immunomodulatory properties of human ASC.

\section{MATERIALS AND METHODS ADIPOSE TISSUE}

Subcutaneous adipose tissue was surgically removed from healthy live kidney donors during the kidney donation procedure after written informed consent, as approved by the Medical Ethical Committee of the Erasmus MC (protocol no. MEC-2006190). Adipose tissue was collected in essential medium alpha (MEM- $\alpha$ ) (Life Technologies, Paisley, UK) supplemented with $100 \mathrm{U} / \mathrm{ml}$ penicillin and $10,000 \mathrm{U} / \mathrm{ml}$ streptomycin $(\mathrm{p} / \mathrm{s})$ and $2 \mathrm{mM}$ L-glutamine (Lonza, Verviers, Belgium).

\section{ASC ISOLATION}

Adipose tissue-derived mesenchymal stem cells were isolated from adipose tissue of five donors as described previously $(5,19)$. In brief, adipose tissue was mechanically disrupted, enzymatically digested with sterile $0.5 \mathrm{mg} / \mathrm{ml}$ collagenase type IV (SigmaAldrich, St. Louis, MO, USA) in RPMI-1640 + glutaMAX (Life Technologies) and $\mathrm{p} / \mathrm{s}$ for $30 \mathrm{~min}$ at $37^{\circ} \mathrm{C}$. Cells were resuspended in ASC culture medium, consisting of MEM- $\alpha$ with $15 \%$ fetal bovine serum (FBS) (Lonza), transferred to a $175 \mathrm{~cm}^{2}$ culture flask (Greiner Bio-one, Essen, Germany), and kept at $37^{\circ} \mathrm{C}, 5 \%$ $\mathrm{CO}_{2}, 20 \% \mathrm{O}_{2}$, and $95 \%$ humidity. Medium was changed every 3-4 days. When $>90 \%$ confluent, ASC were detached using $0.05 \%$ trypsin-EDTA at $37^{\circ} \mathrm{C}$ and either directly used for experiments or frozen until usage. ASC were used for experiments between passages 1 and 5 .

\section{IMMUNOPHENOTYPING BY FLOW CYTOMETRY}

Adipose tissue-derived mesenchymal stem cells were immunophenotyped by flow cytometry after standard culture expansion and after 1 week exposure to hypoxic culture conditions. Subconfluent ASC were trypsinized and washed with FACSFlow (BD Biosciences, San Jose, CA, USA). Cell suspensions were incubated with mouse-anti-human monoclonal antibodies against CD45PerCP, CD73-PE, CD166-PE, HLA-ABC-APC, HLA-DR-APC-Cy7 (all BD Biosciences), and CD105-FITC (R\&D Systems, Abingdon, $\mathrm{UK})$ at room temperature in the absence of light for $15 \mathrm{~min}$. After two washes with FACSFlow, flow cytometric analysis was performed using an eight color FACSCANTO-II with FACSDIVA Software (BD Biosciences) and FlowJo Software (Tree Star, Palo Alto, CA, USA).

\section{HYPOXIC CULTURE CONDITIONS}

Hypoxic conditions were induced by culture of ASC in $1 \% \mathrm{O}_{2}, 5 \%$ $\mathrm{CO}_{2}$, and $94 \% \mathrm{~N}_{2}$ in a $95 \%$ humidified atmosphere. Control cells were kept under normoxic conditions $\left(20 \% \mathrm{O}_{2}\right)$.

\section{LACTATE MEASUREMENTS}

Adipose tissue-derived mesenchymal stem cells were seeded in six-well plates at a concentration of 200,000 cells per well in ASC culture medium and kept under either normoxic or hypoxic conditions. After 3 days, the conditioned medium was collected and frozen at $-80^{\circ} \mathrm{C}$ until usage. A lactate assay kit (BioVision, Milpitas, CA, USA) was used for measurement of lactate levels. In brief, samples were incubated with $50 \mu \mathrm{l}$ of the Reaction Mix for $30 \mathrm{~min}$ at room temperature in the dark. The formed product was measured spectrophotometrically at $570 \mathrm{~nm}$ on a Victor ${ }^{2} 1420$ multilabel plate reader (PerkinElmer, Santa Clara, MA, USA) and corrected for background.

\section{MEASUREMENT OF METABOLIC ACTIVITY BY MTT ASSAY}

Adipose tissue-derived mesenchymal stem cells were seeded in 96-well flat bottom plates at a concentration of 3000 cells per well in $200 \mu \mathrm{l}$ ASC culture medium and kept for 24,48 , or $72 \mathrm{~h}$ under normoxic or hypoxic conditions. Five hours prior to the end of the incubation, $20 \mu \mathrm{l}$ sterile MTT (Sigma-Aldrich) (5 mg $\mathrm{MTT} / \mathrm{ml}$ dissolved in $1 \times \mathrm{PBS}$ ) was added to the wells. Culture medium was then removed and $100 \mu \mathrm{l}$ DMSO added to the cells to dissolve formed crystals. Mitochondrial conversion of MTT was determined by absorbance measurements at $550 \mathrm{~nm}$ wavelength on a Victor $^{2} 1420$ multilabel plate reader.

\section{COLONY FORMING UNIT ASSAY}

Adipose tissue-derived mesenchymal stem cells were seeded at 50 cells per $6 \mathrm{~cm}$ diameter culture dishes in quintuple $\left(3.0 \mathrm{cells} / \mathrm{cm}^{2}\right)$. After 2 weeks of culture under normoxic or hypoxic conditions, medium was removed, the dishes washed with PBS, and fixed in $70 \%$ ethanol. Colonies were stained with $2.3 \%$ crystal violet solution (Sigma-Aldrich) for $30 \mathrm{~min}$. Dishes were then washed with tap water and colonies with a diameter of more than $1 \mathrm{mM}$ counted. Colony forming unit (CFU) efficiency was expressed as the percentage of cells capable of forming colonies.

\section{PROLIFERATION ASSAY}

Adipose tissue-derived mesenchymal stem cells were seeded at a density of 1000 cells $/ \mathrm{cm}^{2}$ in $75 \mathrm{~cm}^{2}$ culture flasks and kept under normoxic or hypoxic conditions for 1 week without medium changes. Cells were then detached by trypsinization, counted, and re-seeded. Population doublings were calculated using the formula $2 \log$ (number of cells at $t_{\mathrm{d} 7} /$ number of cells at $t_{\mathrm{d} 0}$ ). Cumulative population doublings during five consecutive weeks of culture were plotted.

\section{QUANTITATIVE mRNA EXPRESSION}

Adipose tissue-derived mesenchymal stem cells were seeded in sixwell plates at a concentration of $1 \times 10^{5}$ per well in the presence or absence of $20 \mathrm{ng} / \mathrm{ml} \mathrm{TNF} \alpha$ and $50 \mathrm{ng} / \mathrm{ml}$ IFN $\gamma$ and kept under normoxic or hypoxic conditions. After 6,24 , or $72 \mathrm{~h}$, RNAlater (Life Technologies) was added to the cells. RNA was isolated and $500 \mathrm{ng}$ used for cDNA synthesis as described previously (20). Gene expression was determined by real-time RT-PCR using universal PCR master mix (Life Technologies) and Assays-on-demand for hypoxia induced factor $1 \alpha$ (HIF1- $\alpha$ ) (Hs00153153.m1), HIF2$\alpha$ (Hs1026149.m1), VEGF (Hs00173626.m1), indoleamine 2,3dioxygenase (IDO) (Hs00158627.m1), PDL-1 (Hs00204257.m1), TGFß1 (Hs00171257.m1), IL10 (Hs00174086.m1), IL6 (Hs00 174131.m1), and CXCL10 (Hs00171042.m1) (all Applied Biosciences, Foster City, CA, USA) on an ABI PRISM 7700 sequence 
detector (Applied Biosystems). As housekeeping gene expression fluctuates under hypoxia, data was expressed as relative copy number of the PCR products per 500 ng RNA. Relative copy number was calculated using the formula $2^{\text {(40-Ct value) }}$.

\section{IDO ACTIVITY MEASUREMENTS}

Adipose tissue-derived mesenchymal stem cells were cultured for 24 or $72 \mathrm{~h}$ with or without $20 \mathrm{ng} / \mathrm{ml} \mathrm{TNF}-\alpha$ and $50 \mathrm{ng} / \mathrm{ml} \mathrm{IFN-} \gamma$ under normoxic or hypoxic conditions. The tryptophan metabolic activity of IDO was determined by measurement of L-kynurenine in the conditioned medium of five ASC cultures. Thirty percent of trichloroacetic acid was added to the samples at a 1:3 ratio and after $30 \mathrm{~min}$ incubation at $50^{\circ} \mathrm{C}$ the samples were centrifuged at $12,000 \mathrm{rpm}$ for $5 \mathrm{~min}$. Supernatants were then diluted 1:1 in Ehrlich reagent [200 mg 4-dimethylaminobenzaldehyde (Sigma, St. Louis, MO, USA) in $10 \mathrm{ml}$ of glacial acetic acid] in duplicate in a 96-wells flat bottom plate and absorbance was determined at $490 \mathrm{~nm}$ using a multilabel plate reader $\left(\operatorname{VersaMax}^{\mathrm{TM}}\right.$, Molecular Devices, Sunnyvale, CA, USA). L-Kynurenine (Sigma, St. Louis, MO, USA) diluted in unconditioned medium was used as standard.

\section{PBMC ISOLATION}

Peripheral Blood Mononuclear Cells (PBMC) were collected from buffy coats of healthy blood bank donors. PBMC were isolated by density gradient centrifugation using Ficoll Isopaque $(\delta=1.077$, Amersham, Uppsala, Sweden) and frozen $-135^{\circ} \mathrm{C}$ until use.

\section{ANTI-CD3/CD28 LYMPHOCYTE STIMULATION ASSAY}

Peripheral blood mononuclear cells were labeled using the PKH26 Red Fluorescent Cell Linker Kit (Sigma-Aldrich) and stimulated with anti-CD3 antibody $\left(0.5 \mu \mathrm{l} / 5 \times 10^{5}\right.$ cells $)$, anti-CD28 antibody $\left(0.5 \mu \mathrm{l} / 5 \times 10^{5}\right.$ cells $)$, and a goat-anti-mouse antibody ( $1 \mu \mathrm{l} / 5 \times 10^{5}$ cells) for cross-linking (all BD Biosciences). PBMC were seeded in round-bottom 96-well plates at $5 \times 10^{4}$ cells per well and ASC added at 1:2.5, 1:5, 1:10, and 1:20 ratios in MEM- $\alpha$ with $\mathrm{p} / \mathrm{s}$ and $10 \%$ heat inactivated (HI)-human serum. After 3 days of incubation under normoxic or hypoxic conditions, PBMC were collected, washed twice with FACSFlow (BD Biosciences), and incubated with monoclonal antibodies against TCR-FITC (Serotec, Oxford, UK), CD3-AmCyan, CD4-Pacific Blue, CD8PerCP (all BD Biosciences) for $15 \mathrm{~min}$ at room temperature in the absence of light. After two washes with FACSFlow, flow cytometric analysis was performed using an eight color FACSCANTO-II with FACSDIVA Software (BD Biosciences).

\section{STATISTICAL ANALYSIS}

Data were statistically analyzed using Mann Whitney, and KruskalWallis statistical tests. $p<0.05$ was considered significant.

\section{RESULTS}

\section{ASC IDENTITY}

In several previous studies we have demonstrated that the adherent cells of the stromal vascular fraction of human adipose tissue are ASC with properties similar to bone marrow MSC (5, 19, 21). Thus ASC have a spindle-shaped fibroblastic morphology in culture, have a CD $45^{-} \mathrm{CD}^{+} 3^{+} \mathrm{CD} 105^{+} \mathrm{CD} 166^{+}$HLAclass
$\mathrm{I}^{+}$immunophenotype and can differentiate in adipogenic and osteogenic lineages (19) (data not shown).

\section{CULTURE OF ASC UNDER HYPOXIC CONDITIONS}

Under hypoxic conditions, cells are forced to switch to anaerobic metabolism and will produce lactate. In our model, ASC significantly increased lactate concentrations in the culture medium after 3 days of culture under hypoxic conditions $(28.3 \mathrm{mM}$, range 25-31 versus $12 \mathrm{mM}$, range $10-14$, under normoxic conditions) (Figure 1A). Culture of ASC under hypoxic conditions $\left(1 \% \mathrm{O}_{2}\right)$ for $24 \mathrm{~h}$ had no effect on mRNA expression levels of hypoxiainducible factor 1- $\alpha$ (HIF1- $\alpha)$ and HIF2- $\alpha$ (Figure 1B). As hypoxia stabilizes HIF protein, we examined whether gene expression

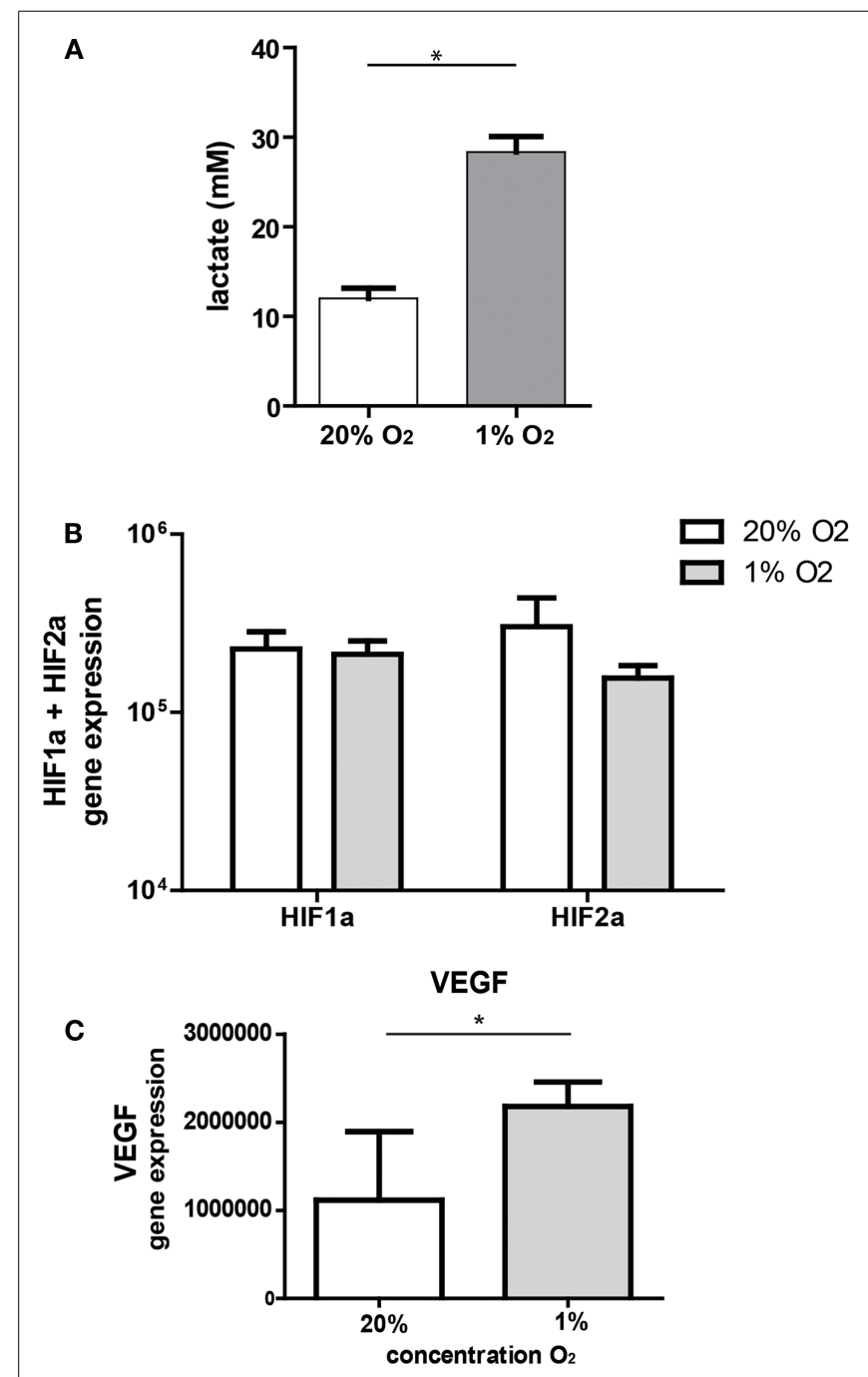

FIGURE 1 | (A) Lactate production by ASC. ASC were cultured under 20 or $1 \% \mathrm{O}_{2}$ for 3 days and medium collected for lactate measurements. Mean with SEM of three experiments is shown. (B) Effect of hypoxia on gene expression of hypoxia-inducible genes; mRNA expression of HIF1- $\alpha$ and HIF2- $\alpha$ by ASC after $24 \mathrm{~h}$ culture under normoxic $\left(20 \% \mathrm{O}_{2}\right)$ and hypoxic $(1 \%$ $\mathrm{O}_{2}$ ) conditions. Mean with SD of four different experiments is shown. (C) mRNA expression of VEGF, downstream of HIF1- $\alpha$ under normoxia and hypoxia. Mean with SD of four different ASC cultures, * Indicates $p<0.05$. 
downstream of HIF was affected by hypoxia in ASC. Expression of VEGF downstream of HIF1- $\alpha$ was significantly increased under hypoxia by nearly a factor two (Figure 1C).

\section{EFFECT OF HYPOXIA ON ASC CHARACTERISTICS}

To study the effect of hypoxia on ASC characteristics, metabolic activity, survival, growth, and proliferation of ASC was examined. Culture of ASC under $1 \% \mathrm{O}_{2}$ for $24 \mathrm{~h}$ up to $72 \mathrm{~h}$ had no effect on ASC metabolic activity and there was no evidence for loss of cell viability, as measured by the mitochondrial reduction of MTT to formazan (Figure 2A). There was a similar increase in the conversion of MTT under normoxic and hypoxic conditions at $24 \mathrm{~h}$ up to $72 \mathrm{~h}$, which reflects the similar increase in cellular metabolic activity under both conditions. Parallel culture of ASC under normoxic and hypoxic conditions for five consecutive weeks demonstrated no difference in population doubling times, which were 2.6 days (range 1.9-3.1), under normoxia and 2.5 days (range 1.9-5.0) under hypoxia. Therefore, cumulative population doublings were the same under both oxygen tensions (Figure 2B). Furthermore, there was no difference in the CFU capacity of ASC cultured under 20 and $1 \%$ $\mathrm{O}_{2}$ (Figure 2C), suggesting oxygen tension does not affect the stemness of ASC. Finally, the immunophenotype of ASC was determined after 10 days of culture under normoxic or hypoxic conditions. Under both conditions, the ASC immunophenotype was $\mathrm{CD} 45^{-} \mathrm{CD} 3^{+} \mathrm{CD} 105^{+} \mathrm{CD} 66^{+} \mathrm{HLA}^{-} \mathrm{I}^{+} \mathrm{HLA}^{-\mathrm{II}^{-}}$(Figure 2D). The expression of CD105 was, however, significantly lower in ASC cultured under hypoxic conditions (MFI 2530) than in ASC cultured under normoxia (MFI 4215).

\section{EFFECT OF HYPOXIA ON THE EXPRESSION OF IMMUNOMODULATORY GENES BY ASC AND IDO ACTIVITY}

It is known that the immunomodulatory capacity of ASC is induced under inflammatory conditions. This was confirmed in the present study by showing that treatment of ASC with IFN$\gamma$ and TNF- $\alpha$ for 6,24 , and $72 \mathrm{~h}$ induced a strong increase in the mRNA expression of immunomodulatory programed death ligand-1 (PD-L1) (102 -fold), CXCL10 ( $10^{6}$-fold), and IDO $\left(10^{5}\right.$ fold). Under hypoxic conditions, ASC maintained the capacity to induce the expression of IDO, PD-L1, and CXCL10 in response to IFN- $\gamma$ and TNF- $\alpha$ to a similar extent as under normoxic concentrations (Figures 3A-C).

To determine whether hypoxia affected the tryptophan depleting activity of IDO in ASC we measured concentrations of L-kynurenine, the breakdown product of tryptophan, in conditioned medium of ASC cultured for 24 or $72 \mathrm{~h}$ with or without TNF- $\alpha$ and IFN- $\gamma$ under 20 or $1 \%$ oxygen. Culture with TNF$\alpha$ and IFN- $\gamma$ strongly increased L-kynurenine levels at 24 and $72 \mathrm{~h}$ (Figures 3D,E). Hypoxia did not affect L-kynurenine levels indicating preserved IDO activity under hypoxic conditions.

Furthermore, TGF- $\beta$, associated with the immunomodulatory capacity of ASC, was expressed by ASC under resting conditions and at similar levels upon stimulation with IFN- $\gamma$ and TNF- $\alpha$. Hypoxia did not affect TGF- $\beta$ expression (data not shown). IL10 was not expressed by ASC under any of the conditions tested (data not shown). Pro-inflammatory IL6 was expressed by ASC, and its expression did not change under low oxygen conditions (data

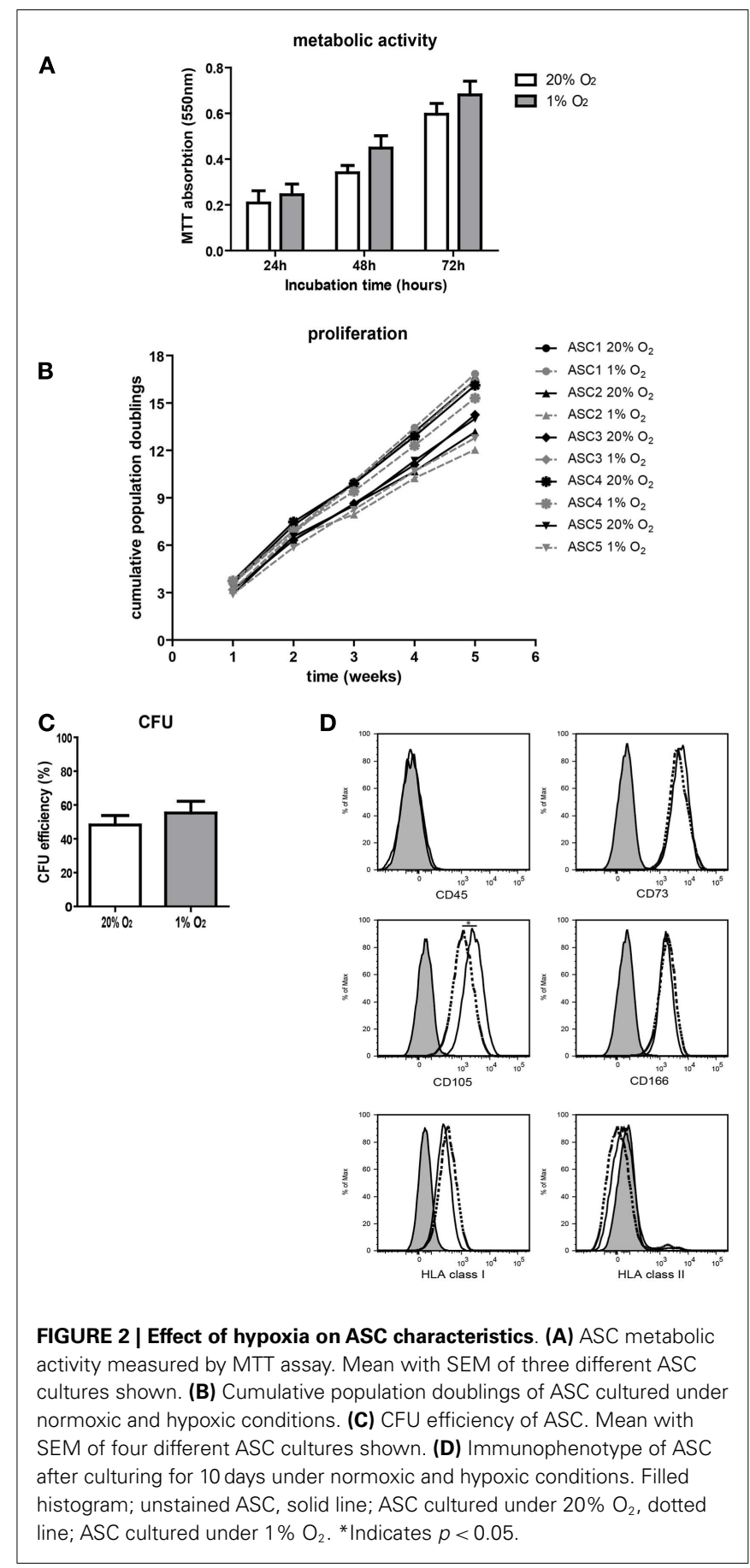

not shown). These data suggest that ASC maintain their capacity to express immunomodulatory factors and respond to inflammatory conditions by activating their immunomodulatory apparatus under hypoxic conditions.

\section{IMMUNOSUPPRESSIVE CAPACITIES OF ASC UNDER HYPOXIA}

To study whether hypoxia influences the in vitro immunosuppressive capacities of ASC, ASC were added to anti-CD3 and anti-CD28 stimulated PKH-labeled allogeneic PBMC. The proliferation of $\mathrm{CD}^{+}$and $\mathrm{CD}^{+} \mathrm{T}$ cells tended to be lower under 


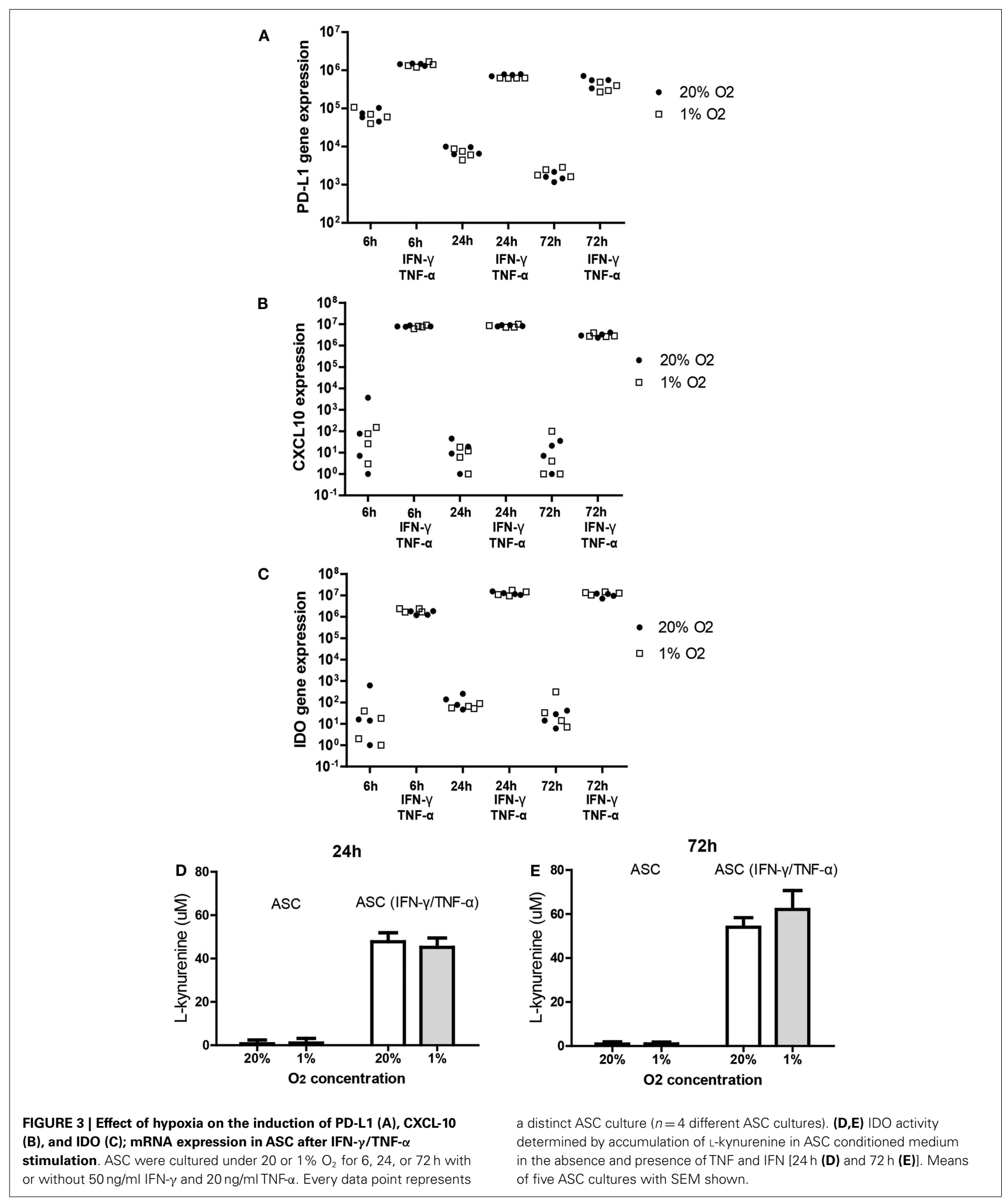

hypoxia than under normoxia, although the difference was not significant. Under normoxia, there was a significant inhibition of $\mathrm{CD}^{+}$and $\mathrm{CD}^{+} \mathrm{T}$ cell proliferation at ASC: PBMC ratios of
1:2.5 (Figures 4A,B). Under hypoxia, inhibition of T cell proliferation was more profound as T cell proliferation was significantly inhibited till ASC:PBMC ratios up to 1:5 (Figures 4A,B). Direct 

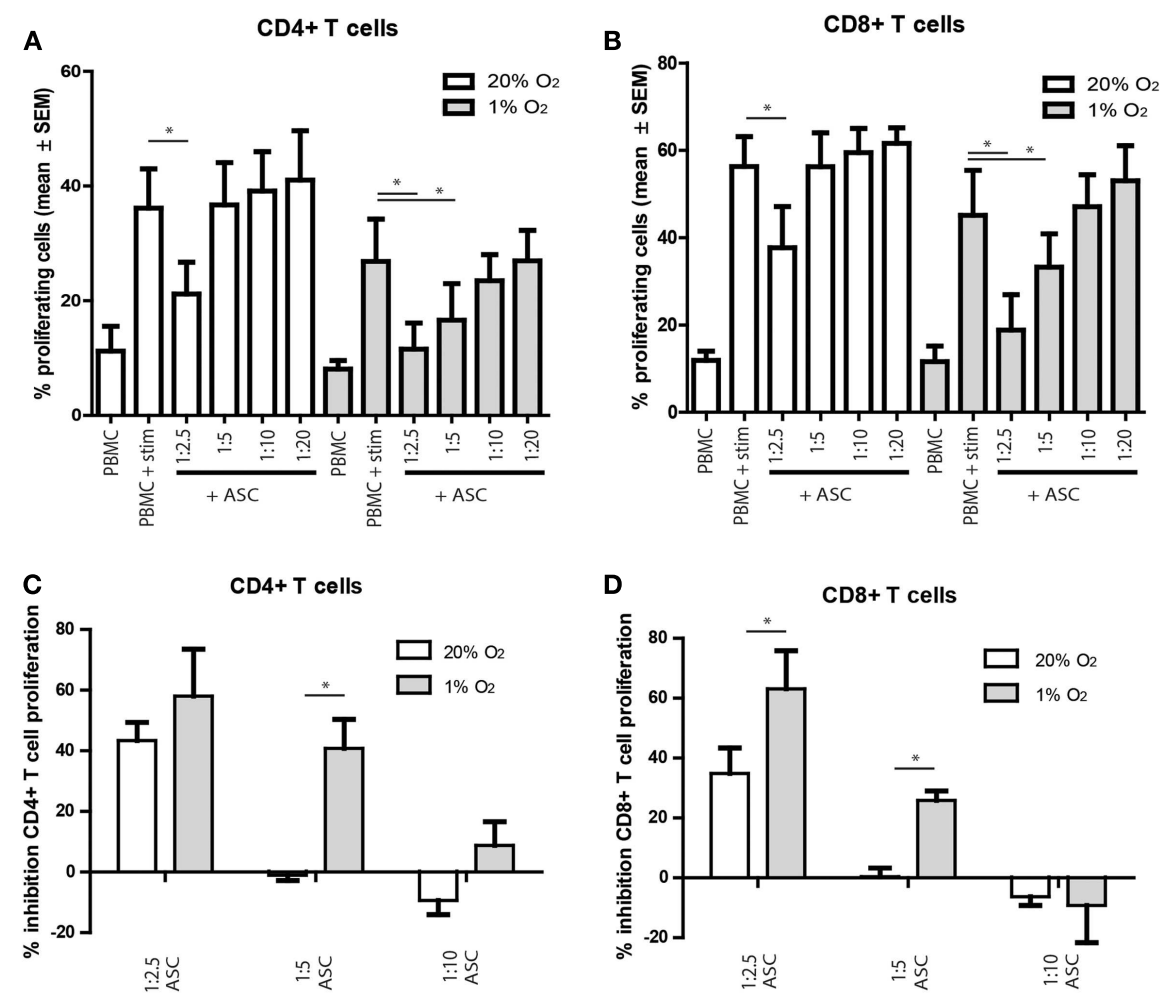

FIGURE 4 | (A-D) PBMC were labeled with PKH and stimulated with anti-CD3/CD28 antibodies. On day 3, the proliferation of $\mathrm{CD} 4^{+}$and $\mathrm{CD} 8^{+} \mathrm{T}$ cells was analyzed by flow cytometry. $(\mathbf{A}, \mathbf{B})$ percentage proliferating cells

comparison of the $\mathrm{T}$ cell inhibition by ASC under normoxia and hypoxia demonstrated that inhibition of $\mathrm{CD}^{+}{ }^{+}$and $\mathrm{CD} 8^{+} \mathrm{T}$ cell proliferation was significantly higher at a $1: 5$ under $1 \%$ oxygen level (Figures 4C,D).

\section{DISCUSSION}

Adipose tissue-derived mesenchymal stem cells possess an assortment of properties that make them suitable for regenerative and immunomodulatory applications. The properties of ASC are affected by changing environmental conditions that induce ASC to adapt a particular function. Oxygen tension is one of these environmental factors. Oxygen tension in tissue fluctuates between 3 and 11\% (22) and may be lower in case of trauma, and such changes may affect the function of ASC. In the present study, we cultured ASC under 20 and $1 \%$ oxygen to examine whether oxygen tension would affect the in vitro properties of ASC.

In the present study we found that ASC were resistant to hypoxic conditions and detected no signs of toxicity or decreased CFU efficiency under low oxygen concentrations. There is some controversy on the effect of hypoxia on the proliferation of bone marrow and ASC, with some studies reporting an inhibitory effect of low oxygen levels on proliferation (23-25), others reporting increased proliferation (26), while we found that ASC proliferation was not affected over at least five passages. There are a number of factors that may influence the outcome of studies, such as the percentage of oxygen used to generate hypoxic conditions with some studies using $1 \%$ oxygen and others up to $5 \%$. Furthermore, the composition of the cell culture medium, in particular the use of serum, and the species of ASC used will affect outcomes. In the present study, the immunophenotype of ASC was only moderately affected by hypoxia, which is in line with earlier studies $(24,25)$. In our hands, only the expression of CD105 (endoglin) was consistently down regulated under low oxygen tension. This is quite surprisingly, as CD105 is known to be up regulated under hypoxia in endothelial cells (27). The consequence of the down regulation of CD105, which is an adhesive molecule, and part of the TGF $\beta$ receptor complex remains to be determined.

In the current study, we further found that a hypoxic preconditioning regimen does not hamper the immunosuppressive properties of ASC. The immunosuppressive function of ASC is induced by inflammatory cytokines such as IFN- $\gamma$ and TNF- $\alpha$ (18, 28). These cytokines stimulate the expression of anti-proliferative IDO and of the inhibitory co-stimulatory molecule PD-L1. The induction of these proteins and the activity of IDO were not affected by hypoxic conditions, indicating that the immunosuppressive machinery of ASC is maintained at low oxygen concentrations. In addition, the strongly enhanced expression of the chemokine CXCL10 under inflammatory conditions was not affected by hypoxia, suggesting that the chemoattractive properties of ASC for immune cells are preserved under low oxygen concentrations. 
Subsequently, we found that culture under $1 \% \mathrm{O}_{2}$ did not hinder the suppressive effects of ASC on T cell proliferation. The percentage of inhibition of T cells by ASC was even increased under hypoxia. Thus although ASC under hypoxia were phenotypically indifferent from ASC under normoxic conditions, they had a more profound effect on $\mathrm{T}$ cell proliferation. One explanation could be that hypoxic conditions shift the balance between $\mathrm{T}$ cell proliferation and the inhibitory effect of ASC. Thus while T cells are affected in their proliferation by hypoxia, as demonstrated earlier (29) and shown in the present study, ASC maintain their suppressive capacity. It is possible that under hypoxic conditions, T cells are more sensitive to low tryptophan concentrations induced by IDO expression in ASC or by PD-L1 induced inhibition of proliferation. ASC therefore have a relatively larger impact on inflammatory conditions and are more effective in inhibiting immune responses under hypoxic conditions, such as in case of trauma, than under normoxic conditions. Alternatively, the enhanced efficacy of ASC to inhibit $\mathrm{T}$ cell proliferation under hypoxia may be explained by the fact that ASC employ additional mechanisms of immunomodulation under hypoxic conditions that were not analyzed in the present study.

\section{REFERENCES}

1. Le Blanc K, Frassoni F, Ball L, Locatelli F, Roelofs H, Lewis I, et al. Mesenchymal stem cells for treatment of steroid-resistant, severe, acute graft-versus-host disease: a phase II study. Lancet (2008) 371(9624):1579-86. doi:10. 1016/S0140-6736(08)60690-X

2. Reinders ME, de Fijter JW, Roelofs $\mathrm{H}$, Bajema IM, de Vries DK, Schaapherder AF, et al. Autologous bone marrow-derived mesenchymal stromal cells for the treatment of allograft rejection after renal transplantation: results of a phase I study. Stem Cells Transl Med (2013) 2(2):107-11. doi:10. 5966/sctm.2012-0114

3. Duijvestein M, Vos AC, Roelofs $\mathrm{H}$, Wildenberg ME, Wendrich BB, Verspaget HW, et al. Autologous bone marrow-derived mesenchymal stromal cell treatment for refractory luminal Crohn's disease: results of a phase I study. Gut (2010) 59(12):1662-9. doi:10.1136/ gut.2010.215152

4. da Silva Meirelles L, Chagastelles PC, Nardi NB. Mesenchymal stem cells reside in virtually all postnatal organs and tissues. J Cell Sci (2006) 119(Pt 11):2204-13. doi:10. $1242 /$ jcs. 02932

5. Hoogduijn MJ, Crop MJ, Peeters AM, Van Osch GJ, Balk AH, Ijzermans JN, et al. Human heart, spleen, and perirenal fat-derived mesenchymal stem cells have immunomodulatory capacities. Stem Cells Dev (2007) 16(4):597-604. doi:10.1089/ scd.2006.0110
6. Nishimori M, Yamada Y, Hoshi K, Akiyama Y, Hoshi Y, Morishima $\mathrm{Y}$, et al. Health-related quality of life of unrelated bone marrow donors in Japan. Blood (2002) 99(6):1995-2001. doi:10. 1182/blood.V99.6.1995

7. Zuk PA, Zhu M,Ashjian P, De Ugarte Human adipose tissue is a source of multipotent stem cells. Mol Biol Cell (2002) 13(12):4279-95. doi:10. 1091/mbc.E02-02-0105

8. Strioga M, Viswanathan S, Darinskas A, Slaby O, Michalek J. Same or not the same? Comparison of adipose tissue-derived versus bone marrow-derived mesenchymal stem and stromal cells. Stem Cells Dev (2012) 21(14):2724-52. doi:10.1089/scd.2011.0722 al. Safety and effect of adipose tissue-derived stem cell implantation in patients with critical limb ischemia: a pilot study. Circ J (2012) 76(7):1750-60. doi: 10.1253/circj.CJ-11-1135

10. Fang B, Song Y, Liao L, Zhang Y, Zhao RC. Favorable response to human adipose tissue-derived mesenchymal stem cells in steroid-refractory acute graftversus-host disease. Transplant Proc (2007) 39(10):3358-62. doi: 10.1016/j.transproceed.2007.02.091

11. Garcia-Olmo D, Herreros D, Pascual I, Pascual JA, Del-Valle E, Zorrilla J, et al. Expanded adipose-derived stem cells for the treatment of complex perianal fistula: a phase DA, Huang JI, Mizuno H, et al.

9. Lee HC, An SG, Lee HW, Park JS, Cha KS, Hong TJ, et

In summary, our data indicates that a reduction of oxygen tension up to at least $1 \%$ does not hamper the immunomodulatory therapeutic efficiency of ASC. This is of relevance as for most clinical purposes, the immunosuppressive capacities of ASC are essential. Assertion of these capacities under hypoxia is crucial as ASC will encounter hypoxic conditions when administered for most, if not all, immunomodulatory applications. Subsequently, as there is evidence that hypoxic pre-conditioning enhances the regenerative potential of ASC $(17,30)$, maintenance of immunosuppressive capacities under hypoxia is needed when hypoxia pre-conditioning will be used for regenerative application. The present study shows that in these situations, the immunomodulatory capacity of ASC is preserved.

\section{ACKNOWLEDGMENTS}

M. J. Leijs was supported by a grant from the Dutch government to the Netherlands Institute for Regenerative Medicine (NIRM). We thank Dr. FJMF Dor, Dr. TCK Tran, Dr. HJAN Kimenai, and Dr. T Terkivatan of the Department of General Surgery for the collection of the adipose tissue.

II clinical trial. Dis Colon Rectum (2009) 52(1):79-86. doi:10.1007/ DCR.0b013e3181973487

12. Goossens GH, Blaak EE. Adipose tissue oxygen tension: implications for chronic metabolic and inflammatory diseases. Curr Opin Clin Nutr Metab Care (2012) 15(6):539-46. doi: 10.1097/MCO.0b013e328358fa87

13. Tsai CC, Chen YJ, Yew TL, Chen LL, Wang JY, Chiu $\mathrm{CH}$, et al. Hypoxia inhibits senescence and maintains mesenchymal stem cell properties through down-regulation of E2A-p21 by HIF-TWIST. Blood (2011) 117(2):459-69. doi: 10.1182/blood-2010-05-287508

14. Nekanti U, Dastidar S, Venugopal $\mathrm{P}$, Totey S, Ta M. Increased proliferation and analysis of differential gene expression in human Wharton's jelly-derived mesenchymal stromal cells under hypoxia. Int J Biol Sci (2010) 6(5):499-512. doi: 10.7150/ijbs.6.499

15. Weijers EM, Van Den Broek LJ, Waaijman T, Van Hinsbergh VW, Gibbs S, Koolwijk P. The influence of hypoxia and fibrinogen variants on the expansion and differentiation of adipose tissue-derived mesenchymal stem cells. Tissue Eng Part A (2011) 17(21-22):2675-85. doi: 10.1089 /ten.tea.2010.0661

16. Valorani MG, Montelatici E, Germani A, Biddle A, D'Alessandro D, Strollo R, et al. Pre-culturing human adipose tissue mesenchymal stem cells under hypoxia increases their adipogenic and osteogenic differentiation potentials. Cell Prolif (2012) 45(3):225-38. doi:10.1111/j. 1365-2184.2012.00817.x

17. Liu L, Gao J, Yuan Y, Chang Q, Liao Y, Lu F. Hypoxia preconditioned human adipose derived mesenchymal stem cells enhance angiogenic potential via secretion of increased VEGF and bFGF. Cell Biol Int (2013) 37(6):551-60. doi: 10.1002/cbin.10097

18. Krampera M, Cosmi L, Angeli R, Pasini A, Liotta F, Andreini A, et al. Role for interferon-gamma in the immunomodulatory activity of human bone marrow mesenchymal stem cells. Stem Cells (2006) 24(2):386-98. doi:10.1634/ stemcells.2005-0008

19. Roemeling-van Rhijn M, Reinders ME, de Klein A, Douben H, Korevaar SS, Mensah FK, et al. Mesenchymal stem cells derived from adipose tissue are not affected by renal disease. Kidney Int (2012) 82(7):748-58. doi:10.1038/ki

20. Hoogduijn MJ, Crop MJ, Peeters AM, Korevaar SS, Eijken M, Drabbels JJ, et al. Donor-derived mesenchymal stem cells remain present and functional in the transplanted human heart. Am J Transplant (2009) 9(1):222-30. doi: 10.1111/j.1600-6143.2008.02450.x

21. Engela AU, Baan CC, Peeters AM, Weimar W, Hoogduijn MJ. Interaction between adipose-tissue derived mesenchymal stem cells and regulatory $\mathrm{T}$ cells. Cell Transplant (2012) 22(1):41-54. doi:10.3727/ 096368912 X636984 
22. Goossens GH, Bizzarri A, Venteclef N, Essers Y, Cleutjens JP, Konings $\mathrm{E}$, et al. Increased adipose tissue oxygen tension in obese compared with lean men is accompanied by insulin resistance, impaired adipose tissue capillarization, and inflammation. Circulation (2011) 124(1):67-76. doi:10.1161/ CIRCULATIONAHA.111.027813

23. Chung DJ, Hayashi K, Toupadakis CA, Wong A, Yellowley CE. Osteogenic proliferation and differentiation of canine bone marrow and adipose tissue derived mesenchymal stromal cells and the influence of hypoxia. Res Vet Sci (2012) 92(1):66-75. doi: 10.1016/j.rvsc.2010.10.012

24. Holzwarth C, Vaegler M, Gieseke F, Pfister SM, Handgretinger $\mathrm{R}$, Kerst $\mathrm{G}$, et al. Low physiologic oxygen tensions reduce proliferation and differentiation of human multipotent mesenchymal stromal cells. $B M C$ Cell Biol (2010) 11:11. doi: 10.1186/1471-2121-11-11
25. Ranera B, Remacha AR, AlvarezArguedas S, Romero A, Vazquez FJ, Zaragoza P, et al. Effect of hypoxia on equine mesenchymal stem cells derived from bone marrow and adipose tissue. BMC Vet Res (2012) 8:142. doi:10.1186/17466148-8-142

26. Carrancio S, Lopez-Holgado $\mathrm{N}$, Sanchez-Guijo FM, Villaron E, Barbado V, Tabera S, et al. Optimization of mesenchymal stem cell expansion procedures by cell separation and culture conditions modification. Exp Hematol (2008) 36(8):1014-21. doi:10.1016/j.exphem.2008.03.012

27. Sanchez-Elsner T, Botella LM, Velasco B, Langa C, Bernabeu C. Endoglin expression is regulated by transcriptional cooperation between the hypoxia and transforming growth factorbeta pathways. $J$ Biol Chem (2002) 277(46):43799-808. doi: 10.1074/jbc.M207160200

28. Crop MJ, Baan CC, Korevaar SS, Ijzermans JN, Pescatori M, Stubbs AP, et al. Inflammatory conditions affect gene expression and function of human adipose tissue-derived mesenchymal stem cells. Clin Exp Immunol (2010) 162(3):474-86. doi:10.1111/j.13652249.2010.04256.x

29. McNamee EN, Korns Johnson D, Homann D, Clambey ET. Hypoxia and hypoxia-inducible factors as regulators of $\mathrm{T}$ cell development, differentiation, and function. Immunol Res (2013) 55(1-3):58-70. doi:10.1007/s12026-012-8349-8

30. Muller J, Benz K, Ahlers M, Gaissmaier C, Mollenhauer J. Hypoxic conditions during expansion culture prime human mesenchymal stromal precursor cells for chondrogenic differentiation in threedimensional cultures. Cell Transplant (2011) 20(10):1589-602. doi: $10.3727 / 096368910 X 564094$

Conflict of Interest Statement: The authors declare that the research was conducted in the absence of any commercial or financial relationships that could be construed as a potential conflict of interest.

Received: 15 May 2013; accepted: 05 July 2013; published online: 18 July 2013. Citation: Roemeling-van Rhijn M, Mensah FKF, Korevaar SS, Leijs MJ, van Osch GJVM, IJzermans JNM, Betjes $M G H$ Baan CC, Weimar $W$ and Hoogduijn MJ (2013) Effects of hypoxia on the immunomodulatory properties of adipose tissue-derived mesenchymal stem cells. Front. Immunol. 4:203. doi: 10.3389/fimmu.2013.00203

This article was submitted to Frontiers in Immunotherapies and Vaccines, a specialty of Frontiers in Immunology. Copyright (C) 2013 Roemeling-van Rhijn, Mensah, Korevaar, Leijs, van Osch, IJzermans, Betjes, Baan, Weimar and Hoogduijn. This is an open-access article distributed under the terms of the Creative Commons Attribution License, which permits use, distribution and reproduction in other forums, provided the original authors and source are credited and subject to any copyright notices concerning any third-party graphics etc. 